\title{
Synthesis and characterization of biocompatible hydroxyapatite coated ferrite
}

\author{
S DEB, J GIRI, S DASGUPTA, D DATTA and D BAHADUR* \\ Department of Metallurgical Engineering and Materials Science, ${ }^{\dagger}$ School of Biomedical Engineering, \\ Indian Institute of Technology, Mumbai 400 076, India
}

MS received 25 March 2003

\begin{abstract}
Ferrite particles coated with biocompatible phases can be used for hyperthermia treatment of cancer. We have synthesized substituted calcium hexaferrite, which is not stable on its own but is stabilized with small substitution of La. Hexaferrite of chemical composition $(\mathrm{CaO})_{0.75}\left(\mathrm{La}_{2} \mathrm{O}_{3}\right)_{0.20}\left(\mathrm{Fe}_{2} \mathrm{O}_{3}\right)_{6}$ was prepared using citrate gel method. Hydroxyapatite was prepared by precipitating it from aqueous solution of $\mathrm{Ca}\left(\mathrm{NO}_{3}\right)_{2}$ and $\left(\mathrm{NH}_{4}\right)_{2} \mathrm{HPO}_{4}$ maintaining $\mathrm{pH}$ above 11. Four different methods were used for coating of hydroxyapatite on ferrite particles. SEM with EDX and X-ray diffraction analysis shows clear evidence of coating of hydroxyapatite on ferrite particles. These coated ferrite particles exhibited coercive field up to $2 \mathrm{kOe}$, which could be made useful for hysteresis heating in hyperthermia. Studies by culturing BHK-21 cells and WBC over the samples show evidence of biocompatibility. SEM micrographs and cell counts give clear indication of cell growth on the surface of the sample. Finally coated ferrite particle was implanted in Kasaulli mouse to test its biocompatibility. The magnetic properties and biocompatibility studies show that these hydroxyapatite coated ferrites could be useful for hyperthermia.
\end{abstract}

Keywords. Bioceramics; hyperthermia; ferrite; biocompatible coating.

\section{Introduction}

Biocompatible materials are finding usage in various types of diagnostic and therapeutic interventions (Bahadur and Giri 2003; Giri et al 2003). Usually in these types of materials, the functional characteristics are retained while being given the advantage of a biocompatible coating. The purpose of this work is to synthesize a biocompatible ferrimagnetic ceramic with significant hysteresis losses. It is known that $\mathrm{CaO} \cdot 6 \mathrm{Fe}_{2} \mathrm{O}_{3}$ has no magnetoplumbite type structure and is not ferrimagnetic, unlike $\mathrm{BaO} \cdot 6 \mathrm{Fe}_{2} \mathrm{O}_{3}$ and $\mathrm{SrO} \cdot 6 \mathrm{Fe}_{2} \mathrm{O}_{3}$ (Yamoto et al 1979; Blanco and Gonzalez 1989). In the present work, stable calcium hexaferrite was prepared by substituting some of the calcium with lanthanum. Coating of hydroxyapatite (HA) onto the prepared hexaferrite was carried out by four different methods to make it biocompatible.

The type of application, which is being intended with these biomaterials, is basically related to the use in hyperthermia treatment of tumour masses. Hyperthermia treatment usually involves an external source of energy. The limitation of using an external energy source is the absorption of energy by the normal tissues as it passes through it to the tumour. This limitation can be avoided by utilizing ferromagnetic bioceramics. Such ceramics when implanted around the tumour will heat the tumour locally

*Author for correspondence through magnetic hysteresis loss. It was reported that hysteresis heating of ferrimagnetic glass ceramic placed into the tumour raised the temperature sufficiently to cause significant delay of tumour regrowth and even permanent control of tumour (Ohura et al 1991; Ebisawa et al 1992).

Evaluation of biocompatibility of synthetic biomaterials (e.g. glass, bioceramics) by in vivo implantation in animals has been used for decades (Castleman et al 1976; Pedersen 1979; Galgut et al 1996). Also uses of in vitro tissue culture techniques have been developed (Kundu et al 1998; Golui et al 2001; Linder et al 2002) to assess the biocompatibility. Here we have used both the techniques and tried to comment effectively on the biocompatibility aspect of the material.

\section{Experimental}

\subsection{Preparation of ferrite}

Ferrite of composition $(\mathrm{CaO})_{0.75}\left(\mathrm{La}_{2} \mathrm{O}_{3}\right)_{0 \cdot 20}\left(\mathrm{Fe}_{2} \mathrm{O}_{3}\right)_{6}$ (Fang et al 1992) was prepared by citrate gel route. Calcium nitrate, ferric citrate and lanthanum oxide were taken as starting chemicals. $\mathrm{La}_{2} \mathrm{O}_{3}$ was dissolved in dilute nitric acid. Metal salt solution and citrate acid were mixed, heated at $40-50^{\circ} \mathrm{C}$ to get clear solution. This mixture was heated at $90^{\circ} \mathrm{C}$ after addition of ethylene glycol until a transparent gel was formed. After gel formation it was kept in an oven 
at $300^{\circ} \mathrm{C}$ for overnight. The gel was converted to powdery mass, which was calcined at different temperatures.

\subsection{Coating of hydroxyapatite}

Four different methods were employed for effective coating of hydroxyapatite on ferrite surfaces.

Method 1: Hydroxyapatite (HA) was prepared using the conventional polycrystalline method. Solutions of $\mathrm{Ca}\left(\mathrm{NO}_{3}\right)_{2}$ $(0 \cdot 1 \mathrm{M})$ and $\left(\mathrm{NH}_{4}\right)_{2} \mathrm{HPO}_{4}(0 \cdot 06 \mathrm{M})$ in distilled water were prepared. The $\mathrm{pH}$ was adjusted to above 11 with concentrated $\mathrm{NH}_{4} \mathrm{OH}$ solution. The $\mathrm{Ca}\left(\mathrm{NO}_{3}\right)_{2}$ solution was vigorously stirred at room temperature and the phosphate solution was added drop wise to it in about $30 \mathrm{~min}$ to produce a milky and somewhat gelatinous precipitate which was then stirred and heated for $32 \mathrm{~h}$. It was then filtered in a Buchner funnel with application of a mild suction. After filtration the compact, sticky, filter cake was dried at $90^{\circ} \mathrm{C}$ for $15 \mathrm{~h}$. Sintering was carried out at $1050^{\circ} \mathrm{C}$ for $1 \mathrm{~h}$ to produce polycrystalline HA (Jarcho et al 1976).

In this method Surfactant Tween-80 was taken in xylene and HA powder was added to this solution. The mixed solution was heated for a few minutes and stirred for $1 \mathrm{~h}$. Calcined $\left(1200^{\circ} \mathrm{C} / 2 \mathrm{~h}\right)$ ferrite particles were added to it and stirred for $4 \mathrm{~h}$. Then it was filtered and dried in an oven.

Method 2: In the second method HA was precipitated onto ferrite from aqueous solution of $\mathrm{Ca}\left(\mathrm{NO}_{3}\right)_{2}$ and $\left(\mathrm{NH}_{4}\right)_{2} \mathrm{HPO}_{4}$ using $\mathrm{NH}_{4} \mathrm{OH}$ to maintain high $\mathrm{pH}$. Ferrite was added to the calcium nitrate solution and the solution was vigorously stirred at room temperature and the phosphate solution was added drop wise. The precipitate was settled overnight. Then it was filtered, dried at $90^{\circ} \mathrm{C}$ and calcined at $1050^{\circ} \mathrm{C}$ for $1 \mathrm{~h}$.

Method 3: In this method positive and negative sols of ferrite were prepared. The positive sol was prepared with $\mathrm{HNO}_{3}$ (at $\mathrm{pH} 4$ ) and the negative sol using tetramethyl ammonium hydroxide and ammonia (at $\mathrm{pH} 12$ ). Both the solutions were stirred with mechanical stirrer for $4 \mathrm{~h}$. Then $0 \cdot 1 \mathrm{M} \mathrm{Ca}\left(\mathrm{NO}_{3}\right)_{2}$ solution was added to the positive sol. A solution of $\left(\mathrm{NH}_{4}\right)_{2} \mathrm{HPO}_{4}(0.06 \mathrm{M})$ was added to the negative sol. This solution was added to the positive sol of ferrite slowly. A white gelatinous precipitate was formed, which was allowed to settle for overnight. Then it was filtered, dried and calcined at $1050^{\circ} \mathrm{C}$ for $1 \mathrm{~h}$ (Massart et al 1981; Towler et al 1996).

Method 4: In this method ferrite was coated by sol-gel method. A mixed ethanol solution of $\mathrm{Ca}\left(\mathrm{NO}_{3}\right)_{2} 4 \mathrm{H}_{2} \mathrm{O}$ and $\mathrm{P}_{2} \mathrm{O}_{5}$ in a $\mathrm{Ca} / \mathrm{P}$ ratio of $1: 6$ was refluxed for $24 \mathrm{~h}$. After cooling at room temperature the ferrite powder was mixed into it and stirred. Then it was filtered and dried at $150^{\circ} \mathrm{C}$. In order to increase the thickness of the coating this pro- cedure was repeated several times. Then the coated sample was calcined at $1050^{\circ} \mathrm{C}$ for $1 \mathrm{~h}$ (Wang and Baptista 1998).

The above four coated samples will be referred to in the text as CLFO-a, CLFO-b, CLFO-c, and CLFO-d, respectively. All the coated samples were separated from excess hydroxyapatite using a magnet.

Characterization of ferrite, hydroxyapatite and coated samples was done using XRD, SEM-EDX and magnetic measurements. XRD was performed using a Diffractometer (Philips PW1710) with $\mathrm{CuK} \alpha$ radiation. Morphological observations of coating and EDX analysis were done with SEM (Cameca SU 30). Magnetization measurements of the bare ferrite as well as coated samples were done as a function of magnetic field and temperature using a PAR Vibrating Sample Magnetometer (VSM).

Biocompatibility tests of the coated samples were carried out using cell culture method as well as by implanting the material in mouse. WBC (white blood cells) and BHK-21 (baby hamster kidney) adherent cells were cultured in presence of these samples in order to test their biocompatibility. The pellets of coated ferrite were sintered at $1050^{\circ} \mathrm{C}$ for $1 \mathrm{~h}$ and these pellets were used for cell culture. All the samples including glassware were first autoclaved at $121^{\circ} \mathrm{C}$ and $1.055 \mathrm{~kg} / \mathrm{cm}^{2}$ pressure for $30 \mathrm{~min}$.

BHK-21 cells were cultured in 24 well culture plate using complete BME (90\% basal media Eagle, $6 \%$ fetal calf serum, 4\% PSGM-antibiotic solution). The materials were kept in the wells at the time of seeding of the culture. In each well $2 \mathrm{ml}$ of complete media was kept, cell suspension was transferred to each well. The set-up was incubated at $37^{\circ} \mathrm{C}$ in $5 \% \mathrm{CO}_{2}$ atmosphere for 3 days, on the third day morphology of the cells were observed under SEM.

Fresh blood was taken in a test tube containing a pinch of EDTA. It was then diluted doubly with phosphate buffered saline (PBS) and centrifuged at $2000 \mathrm{rpm}$ for $15 \mathrm{~min}$ after layering over Histopaque-1077. The interface of the two layers formed was 'buffy' in colour and contained WBC. This buffy region was carefully pipetted out, washed with PBS and transferred to the respective wells of a 24-well plate. Complete media, IMDM (Iscoves modified dulbeccos media, Sigma Chemical Company, USA) supplemented with $6 \%$ human serum and 4\% PSGM (P, penicillin; S, streptomycin; $\mathrm{G}$, gentamycin and $\mathrm{M}$, mycostatin which is an antifungal) was added to each of the wells $(2 \mathrm{ml}$ in each well). The experimental wells contained the sample pellets while the control ones did not contain the samples. Total and viable cell counts (seeding density) were carried out using a hemocytometer. The culture plate was kept in an incubator (maintained at $5 \% \mathrm{CO}_{2}$ and $37^{\circ} \mathrm{C}$ ) for 5 days after seeding the cells. Total and viable cell counts were taken on the third and fifth day from each well including the control well. Cell morphology was studied under SEM. Inductively coupled plasma emission spectroscopy (model no. $8440 \mathrm{M}$ plasma lab) studies were performed taking the supernatant after cell culture. 
In vivo experiment was carried out by implanting CLFO-b in Kasaulli mouse (supplied by Haffkine Biopharmaceutical, Mumbai, India). The material was implanted under the skin of the mouse. On 19th day biopsy taken from the area of material implantation was fixed with $10 \%$ formal saline solution and histopathology was done.

\section{Results and discussion}

Figure 1 shows the X-ray diffractograms of HA sample prepared by conventional polycrystalline method and the ferrite synthesized through citrate gel method and calcined at $1200^{\circ} \mathrm{C} / 2 \mathrm{~h}$ (CLFO). Figure 1 also includes the XRD patterns of the samples coated by various methods. The XRD patterns of figures 1(a) and (b) could be attributed to single phase hexaferrite and hydroxyapatite, respectively. From the XRD patterns of the coated samples it is clear that all the coated samples except CLFO-e contain hydroxyapatite and hexaferrite as two major phases. No peak of hydroxyapatite is observed in the diffractogram of CLFO-e. Here hydroxyapatite may be present in amorphous form.

Figure 2 shows SEM of CLFO and one typical coated sample. Surface morphology of the coated samples is different from that of the bare ferrite as would be expected due to formation of hydroxyapatite coating.

EDX analyses were done to determine the chemical composition of the surface of the sample to support our observations on coating. EDX measurements were carried out on the same point with electrons having accelerating voltages of 20 and $5 \mathrm{keV}$, respectively. As $20 \mathrm{keV}$ electrons have higher energy, they penetrate the sample deeper. On the other hand with $5 \mathrm{keV}$ electron there is a smaller penetration. Therefore, with $20 \mathrm{keV}$ accelerating voltage it is likely to give the chemical composition of essentially the core of the particle. On the contrary with EDX studies with $5 \mathrm{keV}$, it may give the chemical composition essentially of the surface. Results of EDX analysis of a typical sample, CLFO-b, are given in table 1. The table shows that there is a marked difference in the chemical compositions between two measurements representing essentially the core and surface of the particles, respectively. $\mathrm{Ca}$ and $\mathrm{P}$ concentration is much higher on the surface compared to that in the core. Iron is essentially absent on the surface, whereas in the core its concentration is very high as would be expected. The significant increase in the concentration of $\mathrm{Ca}$ and $\mathrm{P}$ on to the sample's surface indicates coating of hydroxyapatite on the particle surface. It was seen from XRD that the hydroxyapatite phase is present along with the hexaferrite phase in the coated sample. All these data confirm that ferrite has successfully been coated with hydroxyapatite. It may be noted that the unreacted HA has been physically separated from coated ferrite by using a strong magnet.
Variation of magnetization $(M)$ with magnetic field $(H)$ at room temperature of bare hexaferrite and hexaferrite coated by sol-gel route (CLFO-d) are shown in figures 3(a) and (b), respectively as typical examples. This figure also shows the variation of magnetization vs temperature for CLFO. All samples show sufficient hysteresis losses

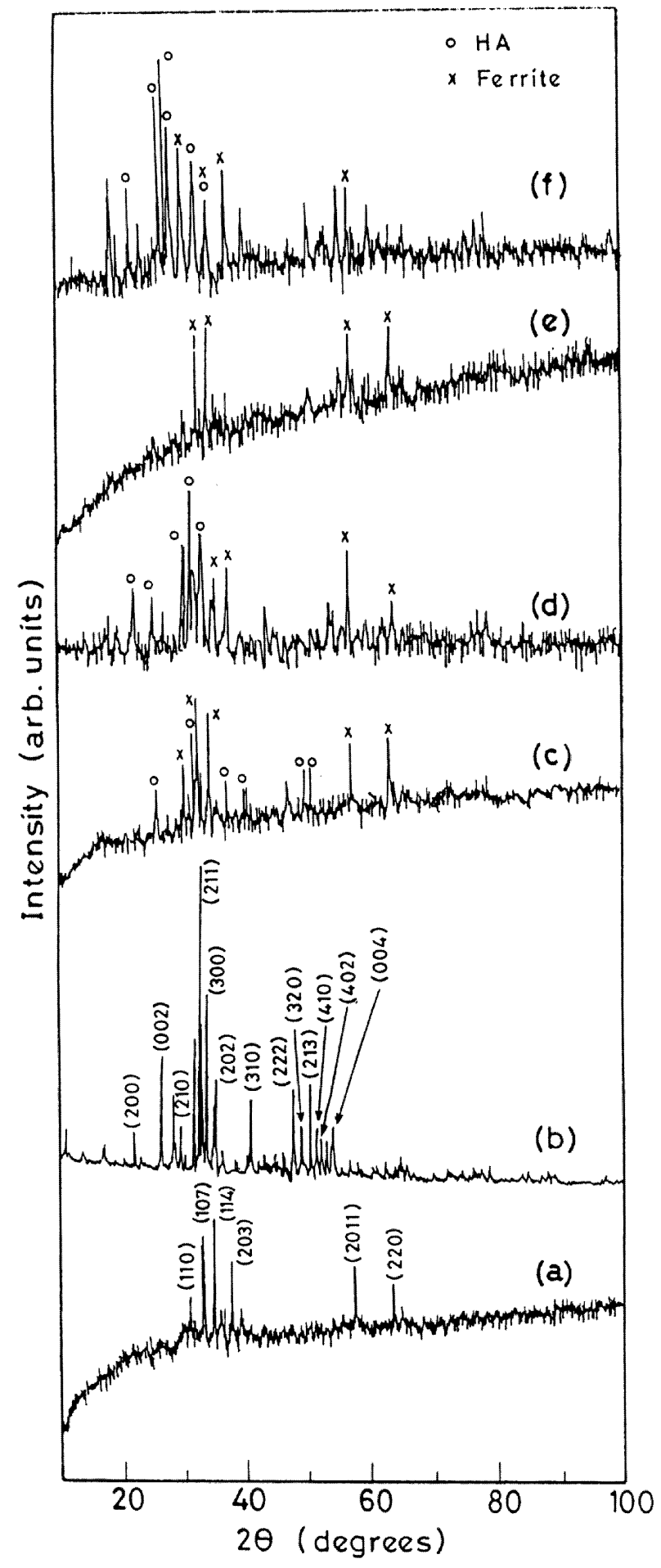

Figure 1. XRD patterns of (a) CLFO, (b) HA, (c) CLFO-a, (d) CLFO-b, (e) CLFO-c and (f) CLFO-d. 
at room temperature. The coated samples show coercivity around $2 \mathrm{kOe}$, which is sufficient for hysteresis loss heating in hyperthermia. Curie temperature $\left(T_{\mathrm{c}}\right)$ of the prepared ferrite is $450^{\circ} \mathrm{C}$, which is comparable to that of barium hexaferrite.

Figures 4(a) and (b) show micrographs of CLFO-b after WBC culture and BHK-21 culture, respectively. It is seen from all the micrographs that there was a marked difference between the microstructure of the samples before and after dipping in the culture fluid. Cells are visible in some of the sample's surfaces. Cells on the surface of sample are visible from figure 4(a). Adherence of proteins on the sample surface is seen in figure 4(b), which is very natural for bioactive materials.

Results of cell counts for WBC culture carried out for different duration are summarized in table 2. Plot of per cent viability as a function of time is shown in figure 5 . This figure shows that except for sample CLFO-d, cells are growing in presence of all the coated samples and per cent viability of the cells are greater in presence of samples than that of control. These results indicate that samples are biocompatible and does not inhibit cell proliferation, rather stimulate it.

Results of ICP analysis of supernatant are summarized in table 3 . It is seen that cell viability is directly proportional to the concentration of iron in the medium. No iron
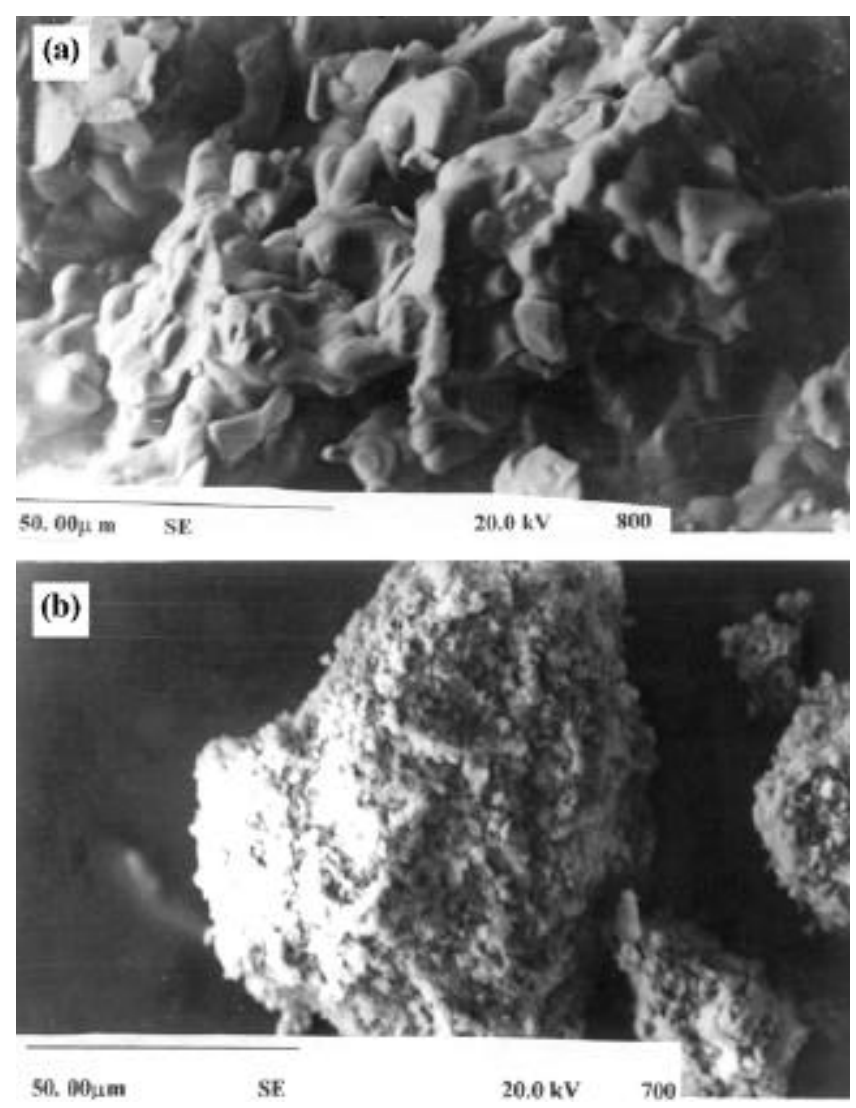

Figure 2. SEM photographs of (a) CLFO and (b) CLFO-d. was detected in the culture medium, which was in contact with bare sample although ferrite was directly exposed to the medium. So it is clear that exchange of iron between sample and medium takes place via HA coating. Due to substitution of $\mathrm{La}^{3+}$ for $\mathrm{Ca}^{2+}$ some $\mathrm{Fe}^{3+}$ may be converted to $\mathrm{Fe}^{2+}$ according to the reaction (Yamoto et al 1979)

$$
\mathrm{Ca}^{2+}+\mathrm{Fe}^{3+} \underset{\mathrm{Ca}}{\stackrel{\mathrm{La}}{\longrightarrow}} \mathrm{La}^{3+}+\mathrm{Fe}^{2+} \text {. }
$$

HA can exchange $\mathrm{Ca}^{2+}$ ion with other cations (Pujari and Patel 1989; Reichert and Binner 1996). Here it exchanges
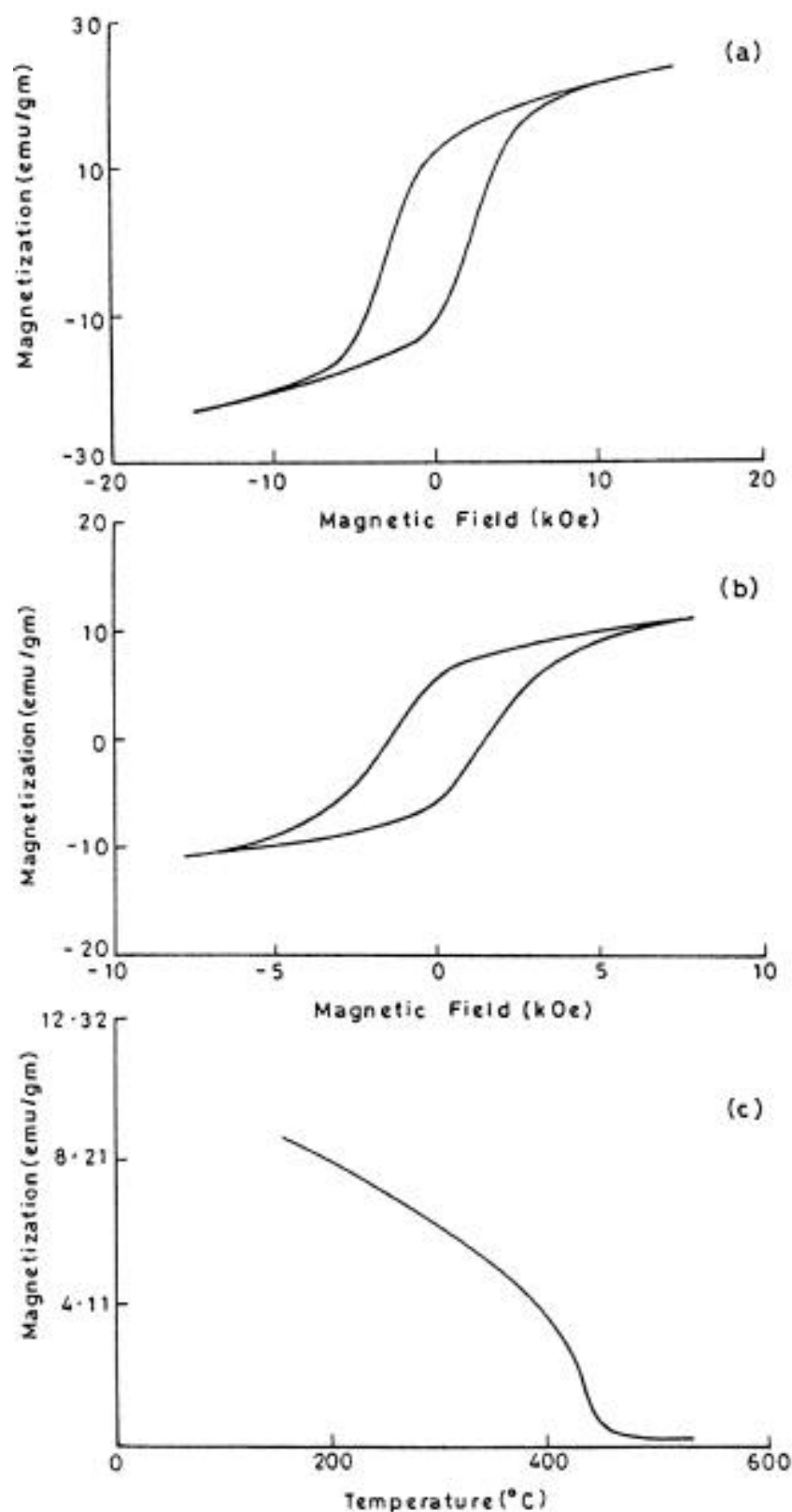

Figure 3. Variation of magnetization $(M)$ of (a) CLFO, (b) CLFO-d with magnetic field $(\mathrm{H})$ at room temperature and $(\mathbf{c})$ CLFO as a function of temperature. 
Table 1. EDX analysis of CLFO-b showing variation of elemental composition between core (with $20 \mathrm{keV}$ ) and surface (with $5 \mathrm{keV}$ ).

\begin{tabular}{|c|c|c|c|c|}
\hline \multirow[t]{2}{*}{ Samples } & \multicolumn{2}{|c|}{$\begin{array}{l}\text { Atomic\% } \\
\text { (accelerating voltage, } 20 \mathrm{keV} \text { ) }\end{array}$} & \multicolumn{2}{|c|}{$\begin{array}{c}\text { Atomic\% } \\
\text { (accelerating voltage, } 5 \mathrm{keV} \text { ) }\end{array}$} \\
\hline & $\mathrm{Fe}$ & $41 \cdot 6$ & $\mathrm{Fe}$ & - \\
\hline \multirow{3}{*}{ CLFO-b } & $\mathrm{Ca}$ & 51.9 & $\mathrm{Ca}$ & $58 \cdot 3$ \\
\hline & $\mathrm{P}$ & 3.9 & $\mathrm{P}$ & $41 \cdot 3$ \\
\hline & $\mathrm{La}$ & $2 \cdot 6$ & $\mathrm{La}$ & $0 \cdot 3$ \\
\hline
\end{tabular}

Table 2. Cell counts taken on the 0th, 3rd and 5th days of incubation of the materials (prepared by different processes) with $\mathrm{WBC}$ and culture medium at $37^{\circ} \mathrm{C}, 5 \% \mathrm{CO}_{2}$. Control signifies well without any synthesized material i.e. with culture medium and WBC only.

\begin{tabular}{lccr}
\hline Sample wells & 0th day & 3rd day & \multicolumn{1}{c}{5 th day } \\
\hline CLFO-a & $15.6 \times 10^{4}$ & $30 \times 10^{4}$ & $56 \times 10^{4}$ \\
CLFO-b & $15.6 \times 10^{4}$ & $44 \times 10^{4}$ & $144 \times 10^{4}$ \\
CLFO-c & $15.6 \times 10^{4}$ & $36 \times 10^{4}$ & $58 \times 10^{4}$ \\
CLFO-d & $15.6 \times 10^{4}$ & $17 \times 10^{4}$ & $19 \times 10^{4}$ \\
Control & $15.6 \times 10^{4}$ & $64 \times 10^{4}$ & $232 \times 10^{4}$ \\
\hline
\end{tabular}

Table 3. Concentration of elements (measured by ICP) in culture supernatants after incubation of the materials (prepared by different processes) with $\mathrm{WBC}$ and culture medium at $37^{\circ} \mathrm{C}$, $5 \% \mathrm{CO}_{2}$. Control signifies well without any synthesized material i.e. with culture medium and WBC only.

\begin{tabular}{lccc}
\hline Samples & Fe (ppm) & $\mathrm{P}(\mathrm{ppm})$ & $\mathrm{Ca}(\mathrm{ppm})$ \\
\hline Control & ND & ND & $55 \cdot 49$ \\
CLFO-a & $1 \cdot 13$ & ND & 131.90 \\
CLFO-b & $6 \cdot 02$ & $152 \cdot 59$ & $129 \cdot 30$ \\
CLFO-c & $2 \cdot 13$ & ND & 112.90 \\
CLFO-d & ND & $142 \cdot 42$ & $157 \cdot 01$ \\
CLFO & ND & ND & 240 \\
\hline
\end{tabular}

$\mathrm{ND}$, not detected $(<0 \cdot 1 \mathrm{ppm})$.

$\mathrm{Ca}^{2+}$ with $\mathrm{Fe}^{2+}$ of the ferrite phase followed by another exchange of $\mathrm{Fe}^{2+}$ with any other cation of medium. Thus iron comes to the culture medium and increases cell proliferation. It is well known that the presence of low concentration of iron stimulates cell viability (Carvalho et al 1996; Okazaki et al 1998). Our results corroborate well with this proposition.

Histopathology of the skin in the area of material implantation (CLFO-b) showed neither any fibrosis nor any other unfavourable tissue reactions (figure 6), indicating compatible nature of the coated sample.

\section{Conclusions}

The unstable calcium hexaferrite has been stabilized by substituting some of the calcium with lanthanum. Coating
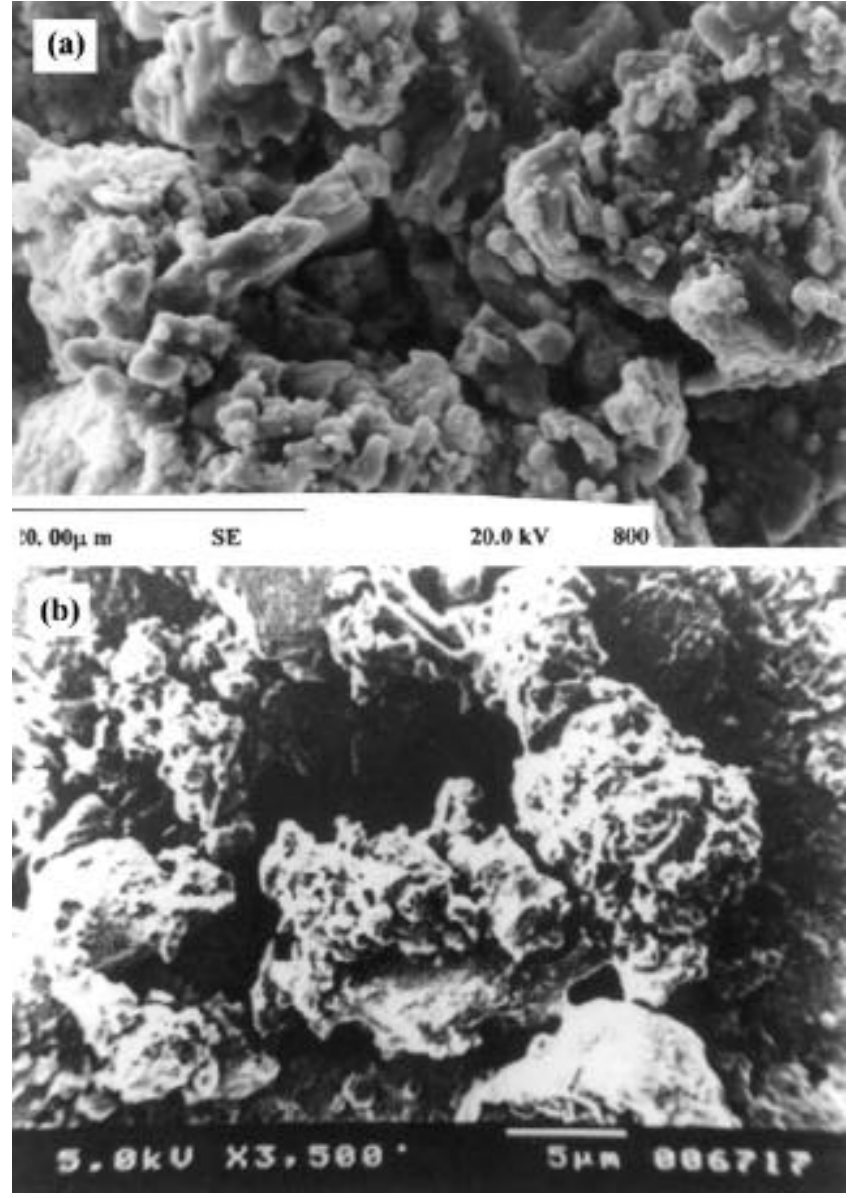

Figure 4. SEM micrographs of (a) protein and cell adherence on CLFO-b after BHK-21 culture and (b) CLFO-b after WBC culture.

of hydroxyapatite on ferrite particle has been done successfully as is evident from XRD and SEM/EDX analysis. The magnetic hysteresis data indicate that these samples exhibit sufficient hysteresis losses to obtain the temperature required for the destruction of the tumorous cells. It was concluded from the cell culture experiments that the coated ferrite samples are biocompatible. SEM analysis of the coated ferrite after the cell culture showed adhered protein in all the samples. Apart from this, few samples exhibited cell growth on the surface. Results of 


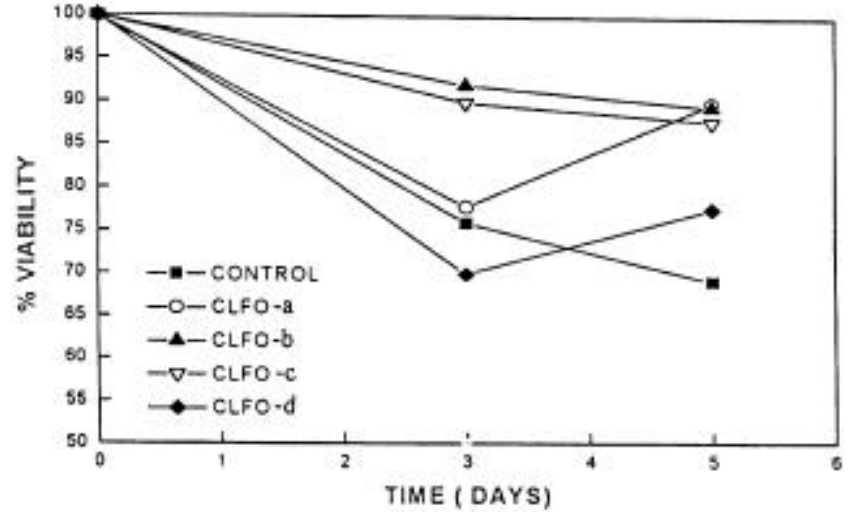

Figure 5. Plot of percent viability of $\mathrm{WBC}$ as a function of time (days). Materials were kept in contact with media containing $\mathrm{WBCs}$ at $37^{\circ} \mathrm{C}, 5 \% \mathrm{CO}_{2}$.

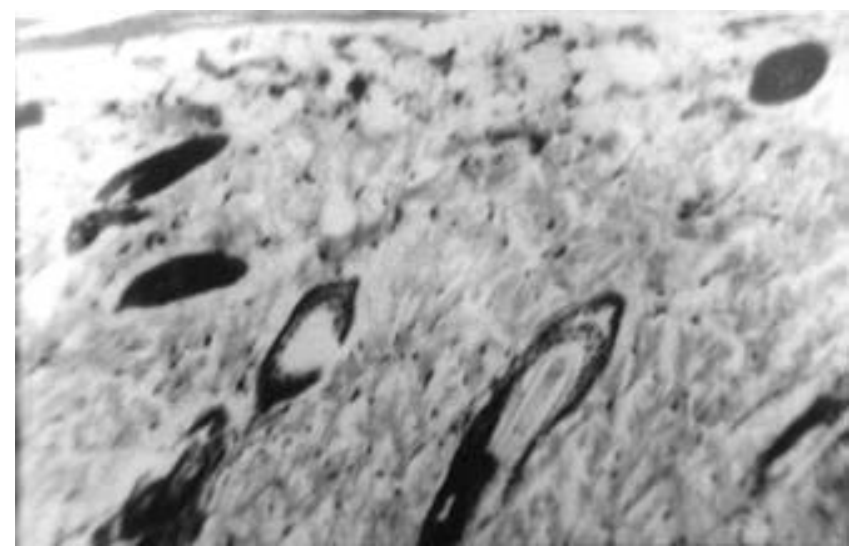

Figure 6. Histopathology (hematoxylin and eosin stained) of skin sample taken from the vicinity of material implantation showed no fibrosis, indicating inert and compatible nature of the material.

histopathology support the above results. All these studies show that the hydroxyapatite coated ferrite samples can be used as thermoseeds in hyperthermia.

\section{Acknowledgement}

Financial support from CSIR, New Delhi, is gratefully acknowledged.

\section{References}

Bahadur D and Giri J 2003 Sādhanā 28639

Blanco A M and Gonzalez F C 1989 J. Phys. D: Appl. Phys. 22210 Carvalho G S, Castanheria M, Diogo I D, Sousa J P, Loon J A and Van Blitterswijk C A 1996 J. Mater. Sci: Mater. Med. 777

Castleman L S, Motzkin S M, Alicandri F P and Bonawit V L 1976 J. Biomed. Mater. Res. 1095

Ebisawa Y, Murashita T and Kokubo T 1992 Proceedings of ICF 6 (eds) J Yamaguchi and M Abe (Tokyo and Kyoto: Japan Society of Powder and Powder Metallurgy) p. 287

Fang Tsang-TSE, Hwang J B and Shiau F S 1992 J. Mater. Sci. Lett. 111217

Galgut P, Waite I and Smith R 1996 J. Oral Rehabil. 2317

Giri J, Ray A, Dasgupta S, Datta D and Bahadur D 2003 Bio. Med. Mater. Engg. (in print)

Golui S, Datta D and Bahadur D 2001 Proceedings of ICF 8 (eds) M Abe and Y Yamazaki (Kyoto, Japan: Japan Society of Powder and Powder Metallurgy) p. 105

Jarcho M, Bolen C H, Thomas M B, Bobick J, Kay J F and Doremus R H 1976 J. Mater. Sci. 112027

Kundu P, Waghode T S, Bahadur D and Dutta D 1998 Med. Biol. Eng. Comp. 36654

Linder S, Pinkowski W and Aepfelbacherm M 2002 Biomaterials 23767

Massart R 1981 IEEE Trans. Magn. 171247

Ohura K, Ikenaga M, Nakamura T, Yamamuro T, Ebisawa Y, Kokubo T, Kotoura Y and Oka M 1991 J. Appl. Biomater. 2153

Okazaki Y, Rao S, Asao S and Tateishi T 1998 Mater. Trans. JIM 391070

Pedersen K N 1979 Acta Odontol. Scand. 37347

Pujari M and Patel P N 1989 J. Solid State Chem. 83100

Reichert J and Binner J G P 1996 J. Mater. Sci. 311231

Sugimoto Y, Hayashi T, Kokubo T, Ohura K and Yamamuro T 1991 Nippon Seramikkusu Kyokai Gakujutsu Ronbundhi 997

Towler P H, Smith J D and Dixon D R 1996 Anal. Chim. Acta 32853

Wang W and Baptista J L 1998 J. Mater. Sci: Mater. Med. 9159

Yamoto H, Kawaguchi T and Nagakura M 1979 IEEE Trans. Magn. 151141 